\title{
Structures and Energetics of Organosilanes in the Gaseous Phase: A Computational Study
}

\begin{abstract}
Ryusuke Futamura, ${ }^{1, \S}$ Miguel Jorge, ${ }^{2}$ José R. B. Gomes ${ }^{1, *}$
${ }^{1}$ CICECO, Department of Chemistry, University of Aveiro, Campus Universitário de Santiago, Aveiro 3810-193, Portugal and ${ }^{2}$ LSRE - Laboratory of Separation and Reaction Engineering - Associate Laboratory LSRE/LCM, Faculdade de Engenharia, Universidade do Porto, Rua Dr. Roberto Frias, 4200-465 Porto, Portugal
\end{abstract}

Corresponding author:

Phone: +351 234401423. Fax: +351 234401470; *e-mail address: jrgomes@ua.pt

$\S$ Present address: Research Center for Exotic Nanocarbons (JST), Shinshu University, 4-17-1 Wakasato, Nagano 380-8553 Japan 


\section{Abstract}

The gas-phase conformations and stabilities of neutral and anionic organosilanes with structure $\left.\left((\mathrm{HO})_{3} \mathrm{Si} \text {-organic linker-Si(OH)}\right)_{3}\right)$, where the organic linker is benzene, ethene or ethane, were studied using density functional theory. The calculations were performed at the B3LYP/6-311+G(2d,2p) level of theory and show that the cis-bis(trihydroxysilyl)-ethene and gauche-bis(trihydroxysilyl)-ethane species are more stable than their trans and anti counterparts. The local geometries of the organic and inorganic fragments in these hybrid compounds are similar to those found in the case of pure silicate compounds or in the parent organic molecules. The calculated enthalpies of deprotonation for these species suggest an acid-base behavior for 1,4-bis(trihydroxysilyl)-benzene species that is intermediate of those calculated for the silicate monomer and for the silicate dimer, while for the cis-bis(trihydroxysilyl)-ethene and gauche-bis(trihydroxysilyl)-ethane an acid-base behavior that is intermediate of those calculated for small and for large pure silicates. It was also found that the calculated charges of the Si atoms are almost independent of the type of carbon atom to which they are bonded and that the charge localized on the organic moiety is always negative even for the neutral species. This information is valuable for the development of molecular force fields for simulating systems involving organosilicates.

Keywords: Density Functional Theory; Periodic Mesoporous Organosilicas; Organosilicates; Atomic Point Charges; Enthalpies of Deprotonation; 


\section{Introduction}

Nanoporous materials have been attracting the attention of researchers for several decades due to their intrinsic characteristics, such as very high surface areas, which make these materials ideal for many applications in nanotechnology and nanoscience ${ }^{1-3}$. Porous materials can adsorb and store large volumes of gases, ${ }^{4}$ which can be effectively removed under adequate conditions, e.g. by changing the temperature. Therefore, these materials are ideal candidates for capturing greenhouse gases, ${ }^{5}$ or for storage of alternative energies of fossil fuels. ${ }^{6}$ Porous materials are finding also application in various industrial processes, acting as water purifiers ${ }^{7}$ or catalysts, ${ }^{8}$ and are being also used in the construction of electrodes possessing optimal pore sizes for sophisticated high-performing capacitors ${ }^{9}$ or in basic research of fluid behavior confined in nanospaces. ${ }^{10-12}$

Over several decades, activated carbons and periodic mesoporous silica (PMS) have been employed as ideal material structures with nanospaces. The pores in these materials have defined slit or cylindrical shapes but show some microscopic disordering. Other more interesting mesoporous hybrid materials have been introduced recently. In fact, three groups independently reported a new type of mesoporous material, which was synthesized using micelle template methods as in the synthesis of PMS but using organosilicates (organic linker is ethane or ethene) instead of silicates as silica sources. ${ }^{13-15}$ These new materials were named periodic mesoporous organosilicas (PMO). Just a few years later, Inagaki et al. ${ }^{16}$ reported the synthesis of an ordered mesoporous organosilica hybrid material, where the organic linker was benzene, having a hexagonal array of mesopores with a lattice constant of $52.5 \AA$, and crystal-like pore walls that exhibit structural periodicity with a spacing of $7.6 \AA$ along the channel direction. These PMOs have two remarkable features which ordinary PMSs do not possess, i.e., molecular order 
periodicity within the pore walls and hybrid organic-inorganic structure, alternating hydrophilic and hydrophobic layers, where each individual organic group is covalently bonded to two or more silicon atoms. ${ }^{17}$ Although the detailed microscopic structure and the formation process of PMOs are not yet fully understood, the molecular ordering of the PMO pore walls was confirmed by large angle XRD measurements. ${ }^{16}$ It was also anticipated that the inorganic parts of PMOs supply strong framework structures and the organic parts are responsible for unique features of the materials, which as the field of PMO progresses, are increasingly responsible for new applications, e.g. in lighting, solar energy, displays and electrically conductive PMO matrices. ${ }^{17}$ Thus, PMOs are still promising materials for modern society with an enormous potential mainly due to the versatility of their chemical compositions. The novel functional PMOs often contain large and complex precursors, whose synthesis and self-assembly may pose a significant challenge despite the knowledge acquired so far. Therefore, the understanding of the PMO formation process and structural details is crucial for creating new types of materials.

Some studies have been carried out recently aiming at elucidating the structure and properties of PMO materials. Commotti et al. reported a 2D NMR study of PMOs synthesized from a benzenesilicate (1,4-bis(triethoxysilyl)benzene) and quantified for the first time the amounts of the different Si condensed species, which were found to be $64.9 \%$, $32.3 \%$, and $2.8 \%$ for the $\mathrm{T}^{3}$ (fully condensed $\mathrm{Si}$ ), $\mathrm{T}^{2}$ (Si unit containing one $\mathrm{OH}$ group), and $\mathrm{T}^{1}$ (Si unit containing two $\mathrm{OH}$ groups) species, respectively. Attributing negligible $\mathrm{T}^{1}$ species to defects in the structure and based on the $\sim 2: 1$ ratio between $\mathrm{T}^{3}$ and $\mathrm{T}^{2}$ species, they suggested that the inorganic layer in the channel walls are constituted by alternate sixand four-member rings of a repeating unit of $\left(\mathrm{T}^{3}-\mathrm{T}^{2}-\mathrm{T}^{3}\right)_{\mathrm{n}}$ along each wall face rather than a regular sequence of six-member silica rings with alternate $T^{3}$ and $T^{2}$ species, i.e., 1:1 ratio between $\mathrm{T}^{3}$ and $\mathrm{T}^{2}$ species of a repeating unit of $\left(\mathrm{T}^{3}-\mathrm{T}^{2}\right)_{\mathrm{n}}$ along each wall face. ${ }^{18}$ Very 
recently, Martinez et al. ${ }^{19}$ reported the results of a periodic density functional theory (DFT) study on the interactions of $\mathrm{CO}, \mathrm{CO}_{2}$ and $\mathrm{CH}_{4}$ molecules with the internal walls of the two channel wall models described above, i.e., $\left(\mathrm{T}^{3}-\mathrm{T}^{2}-\mathrm{T}^{3}\right)_{\mathrm{n}}$ and $\left(\mathrm{T}^{3}-\mathrm{T}^{2}\right)_{\mathrm{n}}$ repeating units. These gaseous molecules interact preferentially with the silanol groups, with calculated adsorption energies of $14.3 \mathrm{~kJ} / \mathrm{mol}, 13.3 \mathrm{~kJ} / \mathrm{mol}$ and $9.2 \mathrm{~kJ} / \mathrm{mol}$ for $\mathrm{CO}, \mathrm{CO}_{2}$ and $\mathrm{CH}_{4}$, respectively, where dispersion was found to account for about one half of the interaction energy. Martinez and Pacchioni introduced some modifications in their models (e.g. inorganic part modified with $\mathrm{Ti}^{-} \mathrm{OH}, \mathrm{Si}^{-} \mathrm{O}^{-}$and $\mathrm{Al}^{-}-\mathrm{OH}$ groups or organic part modified with pyridine or biphenylene groups) and found that the interaction energies were identical or lower than in the case of the original phenylene (organic linker is benzene) species. Soichi et al. studied the Si-C bond stability under acidic and basic conditions of organosilane molecules during polycondensation to organosilica hybrids with NMR and density functional theory (DFT) at the B3LYP//6-311++G(d,p) level of theory, ${ }^{20}$ in order to explain why these bonds in some organosilane precursors are unexpectedly cleaved under such harsh conditions. For example, Si-C bond breakage was found to occur in the case of thiophene-bridged organosilane in basic conditions while almost no Si-C bond rupture was found in the cases where the organic linkers were derived from ethane, ethylene or benzene. ${ }^{20}$

Previously, we have reported a comprehensive computational work devoted to the understanding of the early stages of PMS synthesis. To reach our purposes, detailed atomistic molecular dynamics (MD) simulations were performed for several different aqueous solutions containing a surfactant molecule (decyl-trimethyl-ammonium), neutral and charged silicate monomers and oligomers, and bromide counterions, which were used to model realistic synthesis solutions with concentrations of different silicate species obeying experimental compositions. ${ }^{21-23}$ The potential used for the description of the 
different silicate species was based on DFT calculations. ${ }^{24}$ We have found that anionic silicates interact stronger with the ammonium heads of the cationic surfactants than the bromide ions, and this was found to be related with an increase of the micelle sizes and with the enhancement of silica condensation at the micelle (cooperative templating mechanism). The simulations led to the proposal of a mechanism that validates several previous experimental and modeling studies and answers many controversial issues regarding the synthesis of mesoporous silicas. It would be interesting to adapt the DFT + MD technique used for PMS to hybrid PMO materials, aiming at elucidating the initial stages of the formation mechanism of the latter. To accomplish such task, it is necessary to extend the potential that was employed before in the study of the early stages of the synthesis of PMS. ${ }^{24}$ Hence, DFT calculations were performed to optimize the structures of the organosilicate monomers (neutral and single negative charged silanes with ethane, ethane or benzene linkers), considered as models of the precursor species employed in the synthesis of PMO materials. These calculations are also important in the context of modeling chemical reactions involving organosilicate species.

The full set of computational details is given in section 2 while in section 3 the DFT results are analyzed and discussed, i.e., the calculated partial atomic charges and the optimized bond lengths and angles used to develop the new potential for atomistic MD simulations of the PMO synthesis. Finally, the most important conclusions are summarized in section 4.

\section{Computational details}

The structures of the organosilane species $\left.\left((\mathrm{HO})_{3} \mathrm{Si} \text {-organic linker-Si(OH }\right)_{3}\right)$, namely 1,4-bis(trihydroxysilyl)-benzene, bis(trihydroxysilyl)-ethene, and 
bis(trihydroxysilyl)-ethane, were optimized in the gas-phase by means of density functional theory. The DFT calculations were performed by means of the hybrid B3LYP method, which is based on the ideas of Becke, ${ }^{25}$ and considers a mixture of Hartree-Fock and DFT exchange using the B3 functional, together with the LYP correlation functional due to Lee et al. ${ }^{26}$ as implemented in the Gaussian03 computational code. ${ }^{27}$ The atomic electronic density was described by means of the $6-311+G(2 d, 2 p)$ basis set.

This exchange-correlation functional and basis set were used for computational consistency with the structures optimized previously for silicate monomers as well as for linear and branched oligomers. ${ }^{24}$ In fact, in that work, we have considered the B3LYP functional and some other computational approaches for calculating the enthalpy of the reactions $\mathrm{H}_{2} \mathrm{SiO} \rightarrow \mathrm{HSiO}^{-}+\mathrm{H}^{+}$and $[\mathrm{SiOH}]^{+} \rightarrow \mathrm{SiO}+\mathrm{H}^{+}$but none of the others emerged as a clear and more appropriate choice than B3LYP (c.f. electronic annex A1 in ref. 24). The DFT calculations were also performed on the following negatively charged species: $\left.\left[(\mathrm{HO})_{3} \mathrm{Si} \text {-organic linker-Si(OH}\right)_{2} \mathrm{O}\right]^{-}$and $\left[\mathrm{O}(\mathrm{HO})_{2} \mathrm{Si} \text {-organic linker-Si }(\mathrm{OH})_{2} \mathrm{O}\right]^{2-}$. The refinement of the potential needs the consideration of charged silane species since high $\mathrm{pH}$ conditions, $\mathrm{pH}=\sim 11$, are used in the experimental synthesis of the PMO materials. Under these alkaline conditions, most (organo)silicates are in their deprotonated anionic form. ${ }^{28}$

Due to a large number of conformational degrees of freedom (e.g. cis and trans conformations are possible for the ethene organic linker), the structural optimization of the global minimum for each of the neutral and negatively charged configurations followed the computational strategy below: First of all, at least 10 different initial configurations for each organosilane were designed using information from our previous DFT work on neutral and charged linear, branched and cyclic silicates ${ }^{24}$ and optimized using very tight criteria (int=ultrafine and opt=verytight keywords in the Gaussian code) by B3LYP but 
employing the smaller 6-31G(d) basis set. Please notice that several initial geometries lead to the same final state after optimization with the $6-31 \mathrm{G}(\mathrm{d})$ basis set. Then, the most stable configurations $(\sim 5)$ optimized with the latter approach were further re-optimized at the B3LYP/6-311+G(2d,2p) level of theory. All optimized configurations were confirmed to be potential energy minima with vibrational frequency calculation after the re-optimization. Finally, the most stable configurations were used for subsequent atomic point charge calculations, which considered the Mulliken, ${ }^{29}$ CHelpG (charges from electrostatic potential grid method), ${ }^{30}$ and $\mathrm{NPA}^{31}$ (natural population analysis) approaches.

In order to facilitate the reading, we have considered the following notation for the silica fragments: the neutral monomer, $\mathrm{Si}(\mathrm{OH})_{4}$ is denoted by $\mathrm{SN}$; the ionic monomer, $\left[\mathrm{Si}(\mathrm{OH})_{3} \mathrm{O}\right]^{-}$is denoted by $\mathrm{SI}$ (not to be confused with the silicon atom, $\mathrm{Si}$ ) and the different 1,4-bis(trihydroxysilyl)-benzene molecules are denoted as SNBSN, SIBSN and SIBSI, respectively the neutral, the single and the double negative charged species. Similar notation was used for the organosilanes based on ethane and ethylene, i.e., SNE3SN, SIE3SN and SIE3SI and SNE2SN, SIE2SN and SIE2SI, respectively. With regard to atom type, these will be denoted as follows: $\mathrm{Si}$ is a silicon atom, Oh is a hydroxyl oxygen atom, Oc is a deprotonated oxygen atom (negative charge), Ho is a hydroxyl hydrogen atom, $\mathrm{H}$ is a hydrogen atom in an organic group, and $\mathrm{C}$ is a carbon atom. For the latter two atom types, subscript A refers to a phenyl group, subscript sp2 refers to an ethylene group and subscript sp3 refers to an ethane group. Furthermore, subscripts N and I are used to denote whether atom types belong to a neutral or to an anionic fragment, respectively. 


\section{Results and Discussion}

\subsection{Optimized organosilane structures}

Views of the optimized structures for the neutral and negatively charged organosilicates are shown in Figures 1-3 for organic linkers benzene, ethene and ethane, respectively. Full geometrical details for these molecules are given as supplementary information (Tables S1-S3).

Let us begin with the description of the optimized geometry for 1,4-bis(trihydroxysilyl)-benzene and the anions obtained by single deprotonation at just one or at both silyl groups. In the following discussion, the organosilane molecular structure will be divided into three fragments, i. e., SN or SI units and organic linker. The internal O-Si-O angles in SNBSN are $114.5^{\circ}, 107.5^{\circ}$ and $103.9^{\circ}$ (Fig. 1a and Table $\mathrm{S} 1$ in the Supporting Information). These geometrical parameters optimized in the gaseous phase are in quite good agreement with the experimental results from X-ray powder structural measurements by Cerveau et al., ${ }^{32}$ respectively, $116.4(4)^{\circ}, 112.9(4)^{\circ}$ and $103.4(4)^{\circ}$. As it can be seen, the SN fragments do not possess local C3 symmetry either in the gas or crystal phases. The calculated $\mathrm{C}-\mathrm{C}-\mathrm{C}$ angles of the aromatic ring differ by up to $2.2^{\circ}$ from the values in benzene $\left(120^{\circ}\right)$. The Si-O bond lengths are in the range $1.643 \AA$ to $1.652 \AA$, the Si-C bond lengths are $1.861 \AA$, the HC-CH bond lengths are $1.390 \AA$ and the SiC-CH bond distances are $1.400 \AA$. All these results are in quite good agreement with the X-ray powder diffraction results. ${ }^{32}$ However, it is found that the $\mathrm{Si}-\mathrm{C}$ bonds are shorter in the gas than in the crystal phase while the Si-O bond lengths are included in the range defined by the $\mathrm{X}$-ray values. 


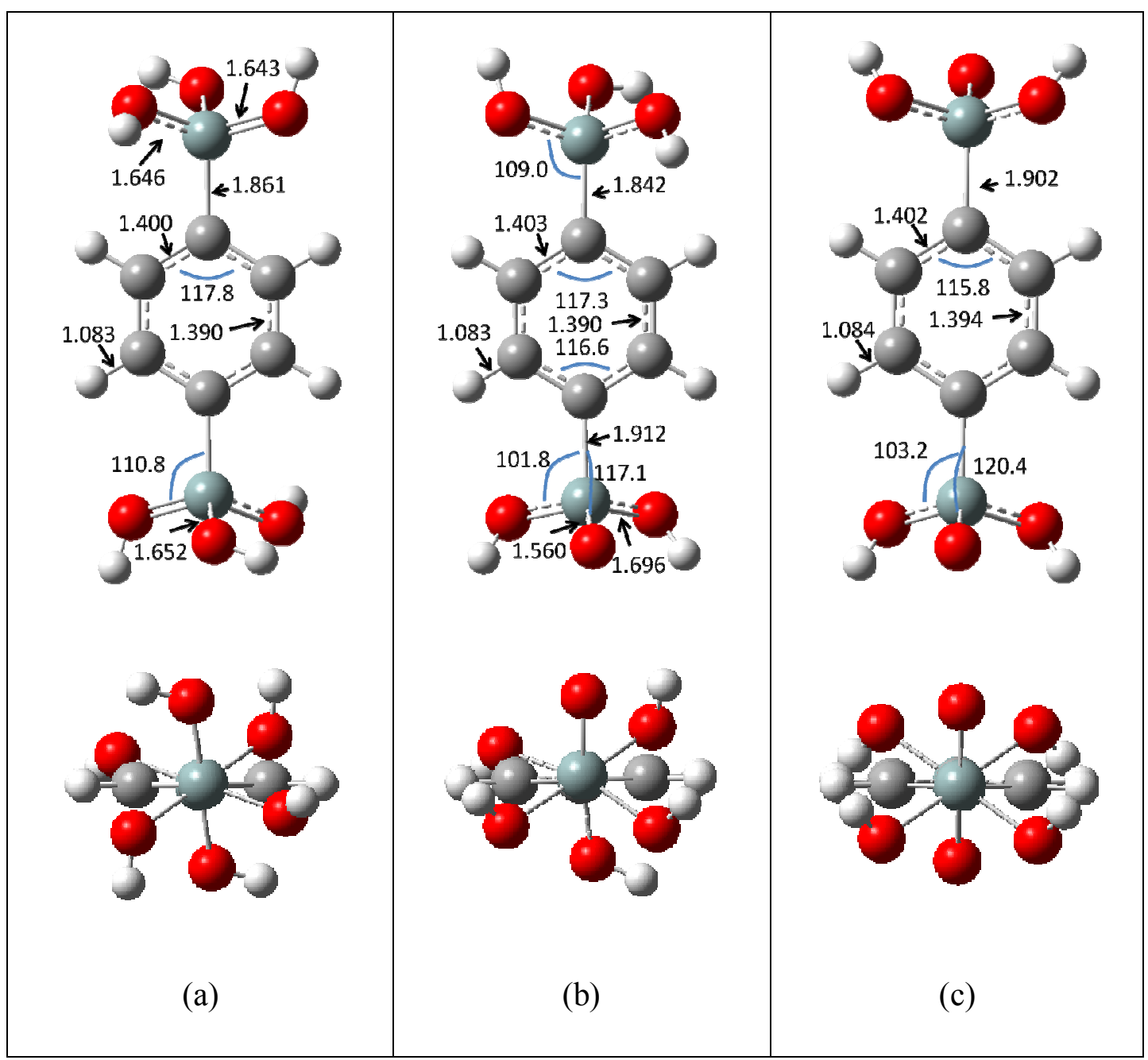

Figure 1.- Side and top views of the optimized configurations for a) SNBSN, b) SIBSN and c) SIBSI molecules. Bond lengths are in $\AA$ and bond angles are in degrees.

The optimized structure for the SIBSN anion is shown in Fig. 1b. As expected, the most notable difference between the structural parameters optimized for the neutral SNBSN species and this anion is observed for the SI fragment. The Si-Oc distance in the SI fragment is shortened by $0.08-0.09 \AA$ and the $\mathrm{Si}-\mathrm{Oh}$ distances in the SI fragment are elongated by $\sim 0.05 \AA$ with respect to Si-Oh bonds in SNBSN molecule. The lengthening of $\mathrm{Si}-\mathrm{Oh}$ bonds occurs as a response to the shorter $\mathrm{Si}-\mathrm{Oc}$ bond, due to stereoelectronic effects caused by orbital overlap since the electronic cloud of Oc atom is larger, and closer to the Si atom, than that of Oh. A similar lengthening (mean value is $0.07 \AA^{23}$ ) was found for the pure silicates (monomers and oligomers) optimized with the same computational approach. 
The Si-Oh bonds in the SN fragment of the SIBSN species are in the range $1.651 \AA-$ $1.663 \AA$ (Table S1), i.e., they are practically unchanged when compared with the SN fragments in SNBSN molecule. The concentration of negative charge in the SI fragment of the SIBSN species induces the elongation of the $\mathrm{Si}-\mathrm{C}$ bond when compared with the $\mathrm{Si}-\mathrm{C}$ bonds in SNBSN, and an opposite but small variation is found for the $\mathrm{Si}-\mathrm{C}$ bond in the $\mathrm{SN}$ fragment of SIBSN when compared with the neutral molecule. These variations are a consequence of charge transfer as discussed below.

In the case of the double charged ion, i. e. SIBSI, Figure 1c, the changes in the SI fragment bond lengths and angles with respect to the $\mathrm{SN}$ fragment in the neutral molecule are similar to those described above for the SI fragment of the SIBSN anion. Hence, the Si-Oc distances are shortened while the Si-Oh and $\mathrm{Si}-\mathrm{C}$ bonds are elongated with respect to Si-Oh and Si-C bonds in SNBSN. Contrasting to what was found for the silica oligomers, ${ }^{24}$ the rigidity of the aromatic ring in these organosilanes prevents the formation of hydrogen bond contacts between the $\mathrm{H}(\mathrm{Oh})$ and $\mathrm{Oc}$ atoms in different SI fragments. Thus, the molecular structures of benzenesilicates are unfolded. As it can be seen in the bottom row of Figure 1, the benzenesilicates show eclipsed configuration of the SN or SI moieties along the Si-C-(...)-C-Si direction as in the crystallographic results by Cerveau et al., ${ }^{32}$ which is expected to facilitate intermolecular hydrogen bonding in condensed phases. This is very relevant for understanding the superior ordering and the periodic arrangement of the structures of PMO materials.

As said above, the synthesis of the type of mesoporous materials considered in this work is usually carried out at high $\mathrm{pH}$ and, therefore, the solutions used in the experimental work are found to present relative proportions of anionic species higher than of neutral species. It is interesting to compare the deprotonation enthalpies of the 
organosilicates with those calculated previously for linear and branched silicates. ${ }^{24}$ The enthalpies of deprotonation are listed in Table 1 and were calculated using the energetic data compiled in Table S4 of the supporting information. When analyzing Table 1, it is important to notice that these deprotonation enthalpies were calculated in the gaseous phase. To obtain values for the enthalpies in solution, solvent effects would need to be considered using a realistic approach, which is beyond the scope of this work. Nevertheless, it is instructive to compare qualitative trends between different organosilicate species.

Table 1. Calculated enthalpies of deprotonation at $T=298.15 \mathrm{~K}$ for the organosilicates considered in this work.

\begin{tabular}{|c|c|c|}
\hline Reaction & $\Delta H_{\text {dep }}(\mathbf{k J} / \mathbf{m o l})$ & $\Delta H_{\text {dep }} / \mathbf{n}(\mathbf{k J} / \mathbf{m o l})^{\mathrm{a}}$ \\
\hline SNBSN $\rightarrow$ SIBSN $+\mathbf{H}^{+}$ & 1448.9 & 1448.9 \\
\hline $\mathrm{SNBSN} \rightarrow \mathrm{SIBSI}+\mathbf{H}^{+}$ & 3131.0 & 1565.5 \\
\hline trans-SNE2SN $\rightarrow$ trans-SIE2SN $+\mathrm{H}^{+}$ & 1449.3 & 1449.3 \\
\hline trans-SNE2SN $\rightarrow$ trans-SIE2SI $+2 \mathrm{H}^{+}$ & 3186.4 & 1593.2 \\
\hline cis-SNE2SN $\rightarrow$ cis-SIE2SN $+\mathbf{H}^{+}$ & 1387.7 & 1387.7 \\
\hline cis-SNE2SN $\rightarrow$ cis-SIE2SI $+2 \mathrm{H}^{+}$ & 3191.8 & 1595.9 \\
\hline anti-SNE3SN $\rightarrow$ anti-SIE3SN $+\mathbf{H}^{+}$ & 1459.5 & 1459.5 \\
\hline anti-SNE3SN $\rightarrow$ anti-SIE3SI $+2 \mathrm{H}^{+}$ & 3194.4 & 1597.2 \\
\hline gauche-SNE3SN $\rightarrow$ gauche-SIE3SN $+\mathbf{H}^{+}$ & 1398.4 & 1398.4 \\
\hline gauche-SNE3SN $\rightarrow$ gauche-SIE3SI $+2 \mathrm{H}^{+}$ & 3203.3 & 1601.7 \\
\hline
\end{tabular}

${ }^{\mathrm{a}}$ Enthalpy of deprotonation divided by the number of $\mathrm{H}^{+}$species involved in the reaction.

It is found that the enthalpy required to remove a proton from SNBSN to yield SIBSN is $25 \mathrm{~kJ} / \mathrm{mol}$ lower than that required to remove a proton from a silicate monomer, $\mathrm{SN}$, via the $\mathrm{Si}(\mathrm{OH})_{4} \rightarrow\left[\mathrm{SiO}(\mathrm{OH})_{3}\right]^{-}+\mathrm{H}^{+}$reaction, but is $46 \mathrm{~kJ} / \mathrm{mol}$ higher than the deprotonation enthalpy calculated for the SN2 dimer and $>\sim 100 \mathrm{~kJ} / \mathrm{mol}$ than the deprotonation enthalpies for larger linear and branched silicates. ${ }^{24}$ Thus, it seems that the SNBSN compound has an acid-base behavior intermediate of those found for SN and SN2 
species. The mean value calculated for single deprotonation at both silicates is intermediate of those computed before for SN2 yielding SISI and for SN3 yielding SISNSI species.

The optimized geometries for the trans and cis configurations of bis(trihydrosilyl)ethene are reported in Fig. 2a. The most striking difference between trans and cis conformers is that in the latter, internal hydrogen bonding between $\mathrm{H}$ and $\mathrm{Oh}$ atoms is possible. This makes the cis isomer more stable than the trans species $(\Delta H=9.9 \mathrm{~kJ} / \mathrm{mol})$, where such H-bond interactions are not possible. This energy difference becomes larger in the case of the anions (Figures $2 b$ and $2 c$ ) since stronger hydrogen bonds are formed between $\mathrm{Oc}$ and $\mathrm{H}$ atoms in different silica fragments and, hence, these species are much more folded than the parent neutral SNE2SN species. The trans to cis enthalpy gain is 71.5 $\mathrm{kJ} / \mathrm{mol}$ and $4.6 \mathrm{~kJ} / \mathrm{mol}$ for SIE2SN and SIE2SI species, respectively. The very large difference between the stability of cis and trans SIE2SN species is due to the formation of two very strong internal hydrogen bonds in the former and concomitant cooperative effect introduced by two other but weaker hydrogen bonds (dashed lines in Figure 2b).

As it is shown in Table 1, the first enthalpy of deprotonation calculated for the trans-SNE2SN species is similar to that calculated for the SNBSN compound (difference of only $0.4 \mathrm{~kJ} / \mathrm{mol}$ ) but that calculated for the cis-SNE2SN compound is lower by $\sim 60$ $\mathrm{kJ} / \mathrm{mol}$. Once again, this difference is due to the presence of a strong internal hydrogen bond in cis-SIE2SN that is not verified in the cases of trans-SIE2SN and SIBSN. The calculated second enthalpies of deprotonation are similar for cis-SIE2SN and trans-SIE2SN, both resulting in the corresponding SIE2SI derivative, but are significantly larger than the first enthalpies of deprotonation calculated for cis-SNE2SN and trans-SNE2SN and than the second enthalpy of deprotonation calculated for the silicate trimer, SN3, yielding the SISNSI species. ${ }^{24}$ 
Finally, from comparison of data in Figures 1 and 2 and in Tables S1 and S2 it is found that the geometrical parameters for the three ethenesilicates are much the same as those calculated for the benzenesilicates.

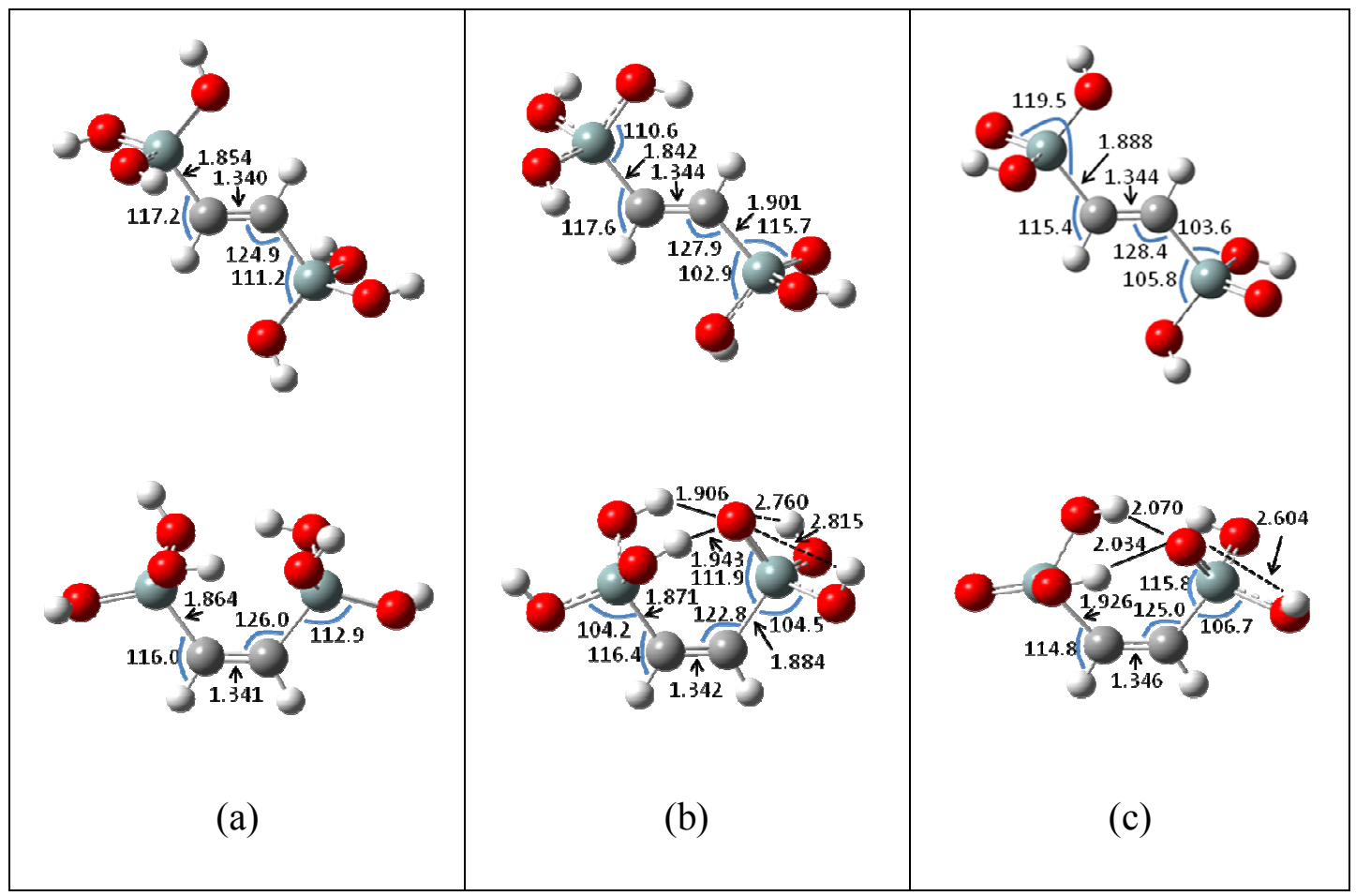

Figure 2.- Optimized trans (top) and cis (bottom) configurations for a) SNE2SN, b) SIE2SN and c) SIE2SI molecules. Bond lengths are in $\AA$ and bond angles are in degrees.

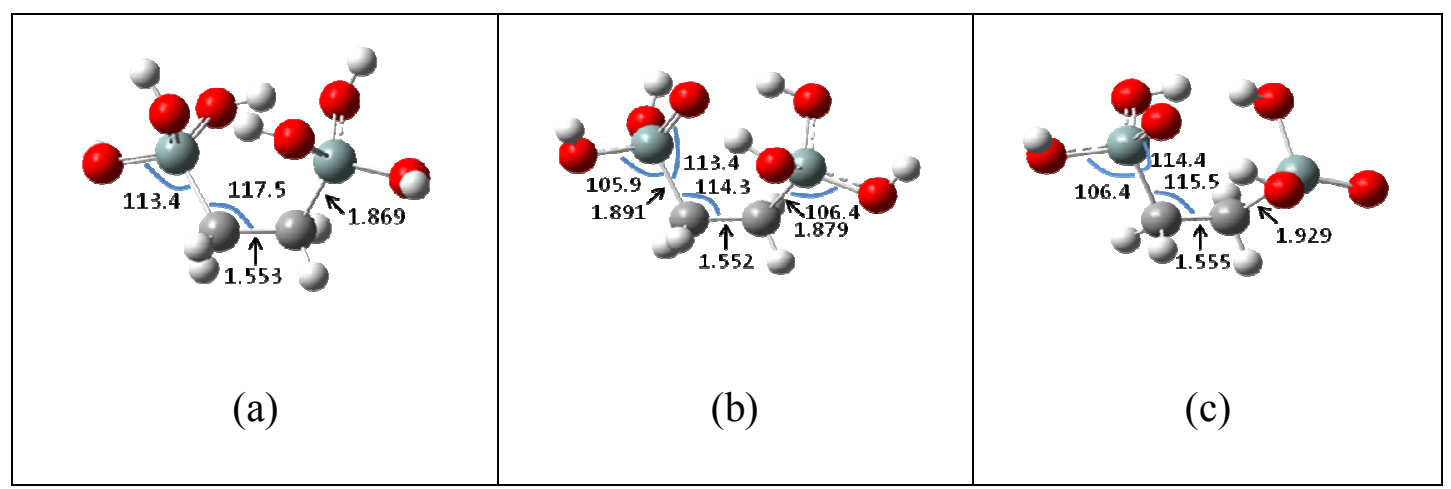

Figure 3.- Optimized structures for a) SNE3SN, b) SIE3SN and c) SIE3SI molecules. Bond lengths are in $\AA$ and bond angles are in degrees.

Views of the optimized geometries for the ethanesilicates and selected geometrical 
parameters are shown in Figure 3 (full details are supplied in Table S3). Both in the neutral and in the anionic species, all the ethane derivatives present gauche-type configuration. Due to the formation of internal hydrogen bonds, the gauche configurations are much more stable than the anti-type configurations (not shown). The calculated enthalpies of deprotonation for the most and for the least stable ethanesilicates are close to their ethene counterparts suggesting that the stability of the silicates species in the gas phase is controlled by the number and nature of the internal hydrogen bonds in these compounds.

In the supplementary information (Tables S5-S10) are given the averages and standard deviations for each bond length and angle calculated over all the gaseous molecules considered above. For the discussion, we will focus separately on bond lengths and bond angles for three different regions. i.e., silica groups (Tables S5 and S8, respectively), organic moieties (Tables S6 and S9, respectively) and the hybrid structure in the region between the organic and inorganic parts (Tables S7 and S10, respectively).

The analysis of the calculated parameters for the silica groups shows that the differences between the $\mathrm{Si}-\mathrm{O}$ and $\mathrm{O}-\mathrm{H}$ bond lengths and $\mathrm{O}-\mathrm{Si}-\mathrm{O}$ and $\mathrm{Si}-\mathrm{O}-\mathrm{H}$ angles in organosilicates and the mean values calculated for the different silicates are smaller than the differences between different silicates, e.g., between linear, branched or cyclic silicates. ${ }^{23,24}$ Thus, the geometrical differences in these bond lengths and bond angles due to the presence of the organic linkers are in the uncertainty intervals defined for the same properties in the silicates. This suggests that the parameters used in our previous MD simulations for such bonds and angles are transferable to the species considered in this work. Similarly, the averages for the bond lengths and bond angles in the organic moieties of the several neutral and anionic organosilicates studied here are almost unchanged when compared with the same parameters in the unsubstituted parent organic molecules, i.e., 
benzene, ethene and ethane. Moreover, it is also evident that the structures of the organic part are negligibly affected by the charges of neighboring silica fragments. In fact, C-C, and $\mathrm{C}-\mathrm{H}$ bond lengths in the case of the neutral 1,4-bis(trihydroxysilyl)-benzene (Fig. 1) and 1,4-bis(trihydroxysilyl)-ethane (Fig. 3) species are identical to those in their respective anions, i.e. differences in the bond lengths are lower than $0.005 \AA$. Similar findings are observed for the $\mathrm{C}=\mathrm{C}$ and $\mathrm{C}-\mathrm{H}$ bonds in neutral and charged 1,4-bis(trihydroxysilyl)-ethene (Fig. 2). This suggests that the parameters for the organic moieties are transferable from neutral to anion or to dianion species.

New parameters for the hybrid region between the organic and inorganic moieties had to be developed here. The analysis of average values in Tables S7 and S10 shows that the Si-C bond length and the $\mathrm{C}-\mathrm{Si}-\mathrm{O}$ angle are almost the same independent of the organic linker, and that the Si-C bond lengths are elongated by $\sim 0.04 \AA$ upon deprotonation in adjacent silica fragments. In charged silicate fragments, there are two types of C-Si-O angles, i. e., C-Si-Oc and $\mathrm{C}-\mathrm{Si}-\mathrm{Oh}_{\mathrm{I}}$, while just a single type is found for neutral fragments, i.e., $\mathrm{C}-\mathrm{Si}-\mathrm{Oh}_{\mathrm{N}}$. The $\mathrm{C}-\mathrm{Si}-\mathrm{Oc}$ angle is larger than the $\mathrm{C}-\mathrm{Si}-\mathrm{Oh}_{\mathrm{N}}$ angle by $5^{\circ}-7^{\circ}$ but the $\mathrm{C}-\mathrm{Si}-\mathrm{Oh}_{\mathrm{I}}$ angle is smaller than the $\mathrm{C}-\mathrm{Si}-\mathrm{Oh}_{\mathrm{N}}$ angle by $7^{\circ}-9^{\circ}$. The variations found in the charged silicates are caused by the repulsion between the $\mathrm{Oc}$ atom and $\mathrm{Oh}$ or $\mathrm{C}$ atoms directly bonded to the same $\mathrm{Si}$, which causes the elongation of bond lengths and the closing of angles in all charged organosilanes when compared with the parent neutral compounds. Finally, the angles C-C-Si and H-C-Si depend on the organic group, but do not depend on the type of Si atom (neutral or ionic).

\subsection{Atomic point charges}

The partial atomic charges were computed with three different standard methods, 
namely, Mulliken, CHelpG and NPA approaches. For further explanation about the differences and meaning of these methods the reader is referred to ref. 33. However, it is meaningful to describe these features briefly in order to understand what they mean. Mulliken and NPA are molecular orbital-based methods and NPA charges are preferred when the chemical nature of atoms is discussed. This is because the NPA charges are much more chemically reasonable compared with the Mulliken charges - in Mulliken analysis, the overlap population is evenly divided between the two neighboring atoms without considering their nature and electronegativity while NPA employs explicitly orthogonalized (natural) atomic orbitals and thus solve the overlap population problem. ${ }^{34}$ The NPA method is almost basis set independent but the charges are unsuited for use when electrostatic properties are of interest (e.g. development of force fields for simulations in aqueous solutions) since their values are usually too positive or too negative when compared with charges obtained from methods which fit charges to match the electrostatic potential. $^{35}$ The CHelpG scheme fits the charges to the electrostatic potential calculated in a regularly spaced grid of points around the molecule under the constraint that the dipole moment is preserved. For this reason, $\mathrm{CHelpG}$ charges are suitable for use as point charges in molecular mechanics force fields for modeling in aqueous environment, ${ }^{36}$ although some erratic behaviors of $\mathrm{CHelpG}$ charges in the description of the chemical nature of silica compounds were reported, ${ }^{37}$ and were found to be superior to charges obtained from molecular-orbital based methods for obtaining multipole moments. ${ }^{35}$ For these historical or practical importances, extensive tables with charges calculated with these three methods for each atomic type (average values) in the different gaseous molecules considered in this work are supplied as supporting information (Tables S11 to S14). Other methods for calculating point charges could be used but they were found to give unrealistic behaviors (e.g., Bader charges predicted a strongly ionic character for several all-silica crystal 
polymorphs) or predict charges that are too low for being compatible with other force fields (e.g. charges calculated with the Hirshfeld method). ${ }^{38}$

The following discussion will mainly consider the NPA charges which are more chemically intuitive for molecules in the gaseous phase than those calculated with the CHelpG approach. As expected from similar calculations performed for gaseous silicates, ${ }^{24}$ highly positive charges are calculated for silicon, negative charges are found on the oxygen atoms and small positive charges on the hydrogen atoms. Furthermore, small negative charges are calculated here for the carbon atoms. Charges for $\mathrm{Oh}_{\mathrm{N}}, \mathrm{Oh}_{\mathrm{I}}, \mathrm{Ho}_{\mathrm{N}}, \mathrm{Ho}_{\mathrm{I}}$ and $\mathrm{Oc}$ atom types in the organosilanes are close to those calculated for silicates. ${ }^{24}$ On the other hand, Si charges connected to $\mathrm{C}$ atoms are lower than the previous values. ${ }^{24}$ It is worth to point out here that there are some differences depending on the method considered for calculating the atomic charges.

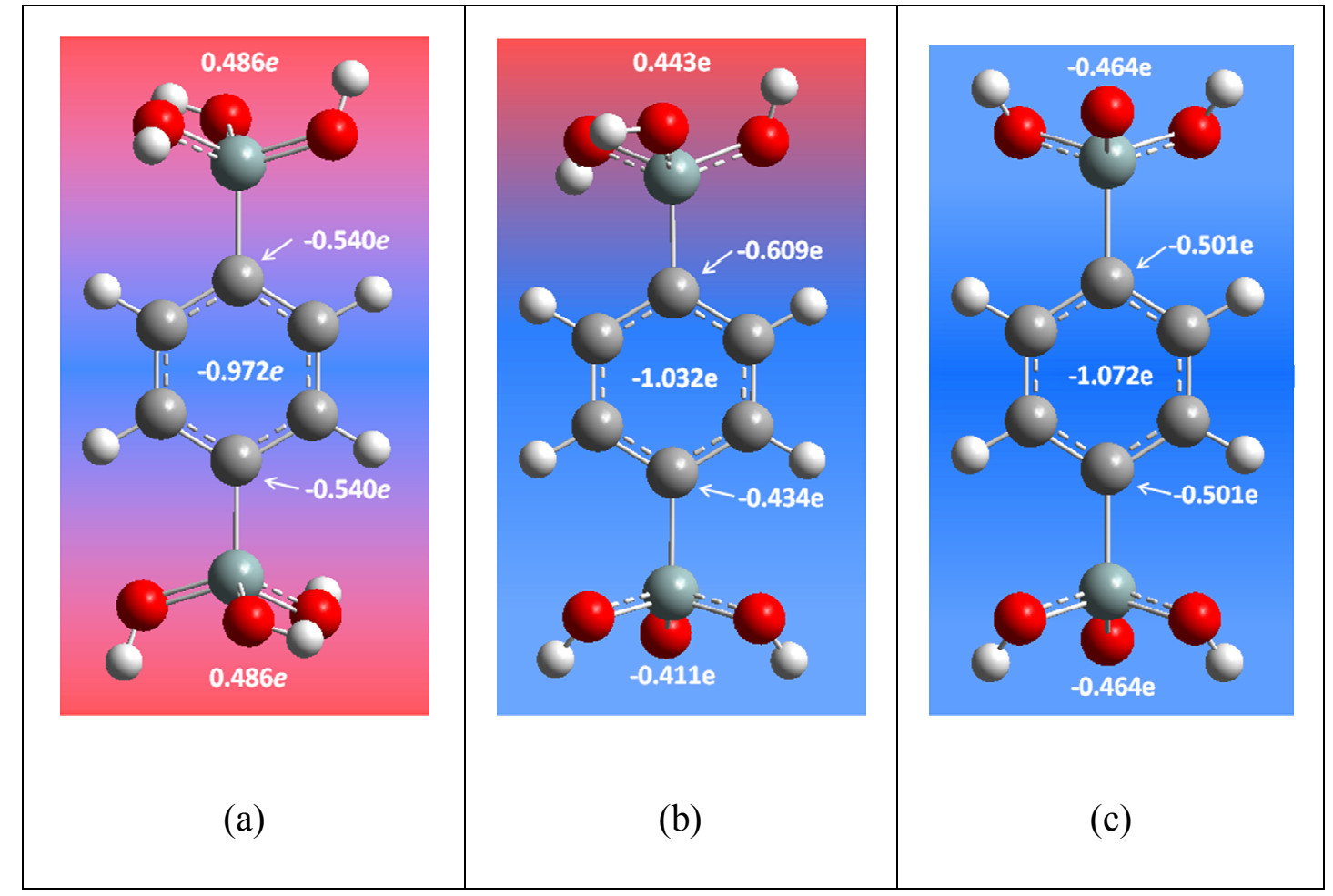

Figure 4.- Total charges in organic and silica fragments for a) SNBSN, b) SIBSN and c) SIBSI molecules. Atomic charges for $\mathrm{C}$ atoms bonded to $\mathrm{Si}$ atoms are also indicated. 
Since we could regard the organic groups as bridging moieties, it is very interesting to compare the partial charges calculated for organosilanes with those for the silicate dimers calculated in our previous work ${ }^{24}$ where two silica (SN or SI) fragments are bridged by an oxygen atom. We can qualitatively mention that the bridging parts are always negatively charged, although the sign of the total charge in the silica fragments depends on the degree of deprotonation in the fragment. In the case of the silicates, ${ }^{24}$ the total charge of an SN fragment was $+0.632 e$ in the case of the neutral dimer (SN2 species or, in the present notation, SNOSN) and $+0.535 e$ in the case of a SNSI dimer (present notation is SNOSI). The total charge of a SI fragment was $-0.253 e$ in the case of SNSI (present notation is SNOSI) and $-0.347 e$ in the case of the SI2 (present notation is SIOSI) molecule. The charges calculated for the bridging oxygens were $-1.265 e,-1.282 e$ and $-1.307 e$ for SN2, SNSI and SI2 species, respectively.

The calculated charges for the different fragments in the benzenesilicates are shown in Figure 4. Clearly, the charges of the bridging parts in the benzenesilicates are less negative than those calculated for the bridging oxygen atom in the pure silicates. Thus, the organic linker is found to visibly affect the charges of the silica fragments, especially the atomic charges of the silicon atoms, which become less positive than silicon atoms in the silicate dimers. Similar findings are observed for cis-ethene, trans-ethene and ethane organosilanes (Supporting Information). As it can be seen in Fig. 4, the total negative charge of the organic moiety is mainly due to the atomic charges of the $\mathrm{C}$ atoms bonded directly to the silicate fragments. Interestingly, the charges in the Si atoms are almost independent of the type of carbon atom to which it is bonded. As suggested in the previous section, the elongated $\mathrm{Si}-\mathrm{C}$ bonds are caused by the negative charges on the deprotonated silicate fragments as it can be seen in Fig. 4, which cause electrostatic repulsion. 


\subsection{Potential parameters}

The full set of potential parameters for the organosilicates is given in Table 2. The charges, bond lengths and bond angles were obtained by averaging the CHelpG and geometric data calculated for the several different configurations of charged and neutral silicates and organosilicates, following our previous approach for silicates [21]. Some of the charges had to be slightly adjusted to ensure that each molecule retained its nominal charge. It is worth noticing that, despite the different approaches used, our values for the point charges of neutral silicates, shown in Table 2, are not very far from those proposed previously by Pereira et al. ${ }^{52}$ based on calculations using a different DFT functional and numerical basis sets.

Table 2. Geometric parameters and point charges for neutral and anionic organosilicates.

\begin{tabular}{|c|c|c|c|c|c|}
\hline atom & charge (a.u.) & bond & length (nm) & angle & value $\left({ }^{\circ}\right)$ \\
\hline $\mathbf{S i}_{\mathbf{N}}$ & 1.206 & $\mathbf{S i}_{N}-\mathbf{O}$ & 0.165 & $\mathrm{Si}_{\mathrm{N}}-\mathrm{Oh}_{\mathrm{N}}-\mathrm{Ho}_{\mathrm{N}}$ & 114.4 \\
\hline $\mathbf{S i}_{\mathbf{I}}$ & 1.332 & $\mathbf{S i}_{\mathrm{I}}-\mathbf{O}$ & 0.169 & $\mathrm{Si}_{\mathbf{I}}-\mathrm{Oh}_{\mathrm{I}}-\mathrm{Ho}_{\mathrm{I}}$ & 109.8 \\
\hline $\mathbf{O h}_{\mathbf{N}}$ & -0.762 & $\mathbf{S i}_{\mathbf{I}}-\mathbf{O}_{\mathbf{c}}$ & 0.158 & $\mathrm{Oh}_{\mathrm{N}}-\mathrm{Si}_{\mathrm{N}}-\mathrm{Oh}_{\mathrm{N}}$ & 109.6 \\
\hline $\mathbf{O h}_{\mathbf{I}}$ & -0.839 & Oh-Ho & 0.097 & $\mathrm{Oh}_{\mathrm{I}}-\mathrm{Si}_{\mathrm{I}}-\mathrm{Oh}_{\mathrm{I}}$ & 104.9 \\
\hline Oc & -1.046 & $\mathbf{S} \mathbf{i}_{N}-\mathbf{C}$ & 0.186 & $\mathrm{Oh}_{\mathrm{I}}-\mathbf{S i}_{\mathrm{I}}-\mathbf{O}_{\mathrm{c}}$ & 114.2 \\
\hline $\mathbf{H}_{\mathrm{sp}} 3$ & 0.060 & $\mathbf{S i}_{\mathbf{I}}-\mathbf{C}$ & 0.190 & $\mathrm{Oh}_{\mathrm{N}}-\mathrm{Si}_{\mathrm{N}}-\mathrm{C}$ & 111.0 \\
\hline $\mathbf{H}_{\mathrm{sp}} 2$ & 0.115 & $\mathrm{C}_{\mathrm{sp}} 3-\mathrm{C}_{\mathrm{sp}} \mathrm{3}$ & 0.153 & $\mathrm{Oh}_{\mathrm{I}}-\mathrm{Si}_{\mathrm{I}}-\mathrm{C}$ & 103.7 \\
\hline $\mathrm{Ho}_{\mathrm{N}}$ & 0.405 & $\mathrm{C}_{\mathrm{sp}} 3-\mathrm{H}_{\mathrm{sp}} 3$ & 0.109 & $\mathbf{O}_{\mathbf{c}}-\mathbf{S i}_{\mathbf{I}}-\mathbf{C}$ & 116.4 \\
\hline $\mathrm{Ho}_{\mathrm{I}}$ & 0.376 & $\mathrm{C}_{\mathrm{sp}} 2-\mathrm{C}_{\mathrm{sp}} 2$ & 0.134 & $\mathrm{Si}-\mathrm{C}_{\mathrm{sp}} 3-\mathrm{C}_{\mathrm{sp}} 3$ & 115.4 \\
\hline $\mathbf{H}_{\mathbf{A}}(\mathbf{S N})$ & 0.115 & $\mathrm{C}_{\mathrm{sp}} 2-\mathrm{H}_{\mathrm{sp}} 2$ & 0.108 & $\mathrm{Si}-\mathrm{C}_{\mathrm{sp}} 2-\mathrm{C}_{\mathrm{sp}} 2$ & 126.0 \\
\hline $\mathbf{H}_{\mathbf{A}}(\mathbf{S I})$ & 0.115 & $\mathbf{C}_{\mathrm{A}}-\mathrm{C}_{\mathrm{A}}$ & 0.140 & $\mathrm{Si}-\mathrm{C}_{\mathrm{A}}-\mathrm{C}_{\mathrm{A}}$ & 120.0 \\
\hline $\mathrm{C}_{\mathrm{sp}} 3(\mathrm{SN})$ & -0.255 & $\mathrm{C}_{\mathrm{A}}-\mathrm{H}_{\mathrm{A}}$ & 0.108 & $\mathrm{Si}-\mathrm{C}_{\mathrm{sp}} 3-\mathrm{H}_{\mathrm{sp}} 3$ & 109.9 \\
\hline $\mathrm{C}_{\mathrm{sp}} 3(\mathrm{SI})$ & -0.480 & & & $\mathrm{Si}-\mathrm{C}_{\mathrm{sp}} 2-\mathrm{H}_{\mathrm{sp}} 2$ & 117.6 \\
\hline $\mathrm{C}_{\mathrm{sp}} 2(\mathrm{SN})$ & -0.250 & & & $\mathrm{C}_{\mathrm{sp}} 3-\mathrm{C}_{\mathrm{sp}} 3-\mathrm{H}_{\mathrm{sp}} 3$ & 110.7 \\
\hline
\end{tabular}




\begin{tabular}{ll||l|ll}
$\mathbf{C}_{\mathrm{sp}} \mathbf{2}(\mathbf{S I})$ & -0.475 \\
$\mathbf{C}_{\mathrm{A}}(\mathbf{S N})$ & -0.135 \\
$\mathbf{C}_{\mathrm{A}}(\mathbf{S I})$ & -0.360 \\
$\mathbf{C}_{\mathrm{A}}(\mathbf{H}, \mathbf{S N})$ & -0.115 \\
$\mathbf{C}_{\mathrm{A}}(\mathbf{H}, \mathbf{S I})$ & -0.115 & $\mathbf{H}_{\mathrm{sp}} \mathbf{3}-\mathbf{C}_{\mathrm{sp}} \mathbf{3}-\mathbf{H}_{\mathrm{sp}} \mathbf{3}$ & 107.8 \\
$\mathbf{C}_{\mathrm{sp}} \mathbf{2}-\mathbf{C}_{\mathrm{sp}} \mathbf{2}-\mathbf{H}_{\mathrm{sp}} \mathbf{2}$ & 120.0 \\
$\mathbf{C}_{\mathrm{A}}-\mathbf{C}_{\mathrm{A}}-\mathbf{C}_{\mathrm{A}}$ & 120.0 \\
& & $\mathbf{C}_{\mathrm{A}}-\mathbf{C}_{\mathrm{A}}-\mathbf{H}_{\mathrm{A}}$ & 120.0 \\
\end{tabular}

Interestingly, the parameters regarding the silicate and the organic moieties in the organosilicates are identical to those obtained before for silicates (linear, branched and cyclic) and to those available for the parent organic molecules (benzene, ethylene and ethane), respectively. In fact, the most important changes refer to the parameters involving the linking of the organic and inorganic parts, i.e., the Si-C bond length and the C-Si-O, C-C-Si and H-C-Si bond angles. Fortunately, in terms of force field transferability, some of these parameters were found to be almost independent of which organic linker is considered, i.e., the parameters are much the same if the linker is ethane, ethylene or benzene. Importantly, it was found that the $\mathrm{C}-\mathrm{C}-\mathrm{Si}$ and $\mathrm{H}-\mathrm{C}-\mathrm{Si}$ bond angles depend on the organic linker but do not depend on the global charge (neutral, anion or dianion) of the organosilicate species while the $\mathrm{Si}-\mathrm{C}$ bond length and the $\mathrm{C}-\mathrm{Si}-\mathrm{O}$ bond angle do not depend on the organic linker but depend on the global charge of the organosilicate.

In conclusion, the potential parameters optimized in this work for molecular simulations involving organosilanes in solution can be combined with those developed before for silicates possessing different geometries, e.g. linear, branched, cyclic, and different degrees of deprotonation.

\section{Conclusions}

This paper presents the results of a density functional theory study, with a considerably large basis set, on the geometries, energies and point charges of neutral, 
singly-deprotonated and doubly-deprotonated organosilicate molecules (1,4-bis(trihydroxysilyl)-benzene, bis(trihydroxysilyl)-ethene and bis(trihydroxysilyl)-ethane) in the gaseous phase. Several possible starting geometries were considered to assure that the most stable conformer was duly characterized for each of these species. The bond lengths and angles for the neutral and anionic organosilanes were discussed in detail. The analysis of the optimized structures for the organosilanes shows that the local geometries of the silica fragments of the organosilicate are similar to those found in the pure silicate compounds and that the local geometries of the organic part of the organosilicates are similar to those found in the parent organic molecules. Since our aim is to develop a new potential for classical molecular dynamics simulations of organosilicates in solution, these similarities are very important for transferability of the potential.

From the calculated enthalpies of deprotonation it is concluded that the 1,4-bis(trihydroxysilyl)-benzene species has an acid-base behavior that is intermediate of those calculated for the SN (silicate monomer) and for the SN2 (silicate dimer). The acid-base behavior of the 1,4-bis(trihydroxysilyl)-benzene is similar to those found for the least stable silanes with ethene or ethane as the organic linker, i.e., it is similar to the behaviors of trans-bis(trihydroxysilyl)-ethene and anti-bis(trihydroxysilyl)-ethane compounds, respectively. For the most stable conformers of the latter organosilanes, i.e., cis-bis(trihydroxysilyl)-ethene and gauche-bis(trihydroxysilyl)-ethane, the calculated enthalpies of deprotonation are lower than those calculated for the SN and SN2 species, suggesting a behavior that is intermediate of those found for small (up to $2 \mathrm{Si}$ atoms) and larger pure silicates.

The partial atomic charges of the organosilicates were calculated with three 
different approaches. From a natural population analysis it is found that the calculated charges of the Si atoms are almost independent of the type of carbon atom to which they are bonded but the charges on the neutral silicate fragments are less positive and the charges on the anionic silicate fragments are more negative when compared with those in the pure silicates, either the neutral SN2 or the singly-deprotonated SNSI species. Finally, since the silicate fragments are separated by the organic linker in the case of the organosilanes, the charge variation in the SN unit on going from SNXSN to SNXSI and the charge variation in the SI unit on going from SIXSN to SIXSI is less important than the variations noticed for the pure silicate species.

\section{Acknowledgements}

This work is supported by projects PTDC/EQU-EQU/099423/2008, PTDC/QUI-QUI/109914/2009, PEst-C/EQB/LA0020/2011 and PEst-C/CTM/LA0011/2011, financed by FEDER through COMPETE - Programa Operacional Factores de Competitividade and by FCT - Fundação para a Ciência e a Tecnologia, Lisbon, Portugal. Acknowledgement is also due to Programa Ciência 2007. 


\section{References}

1. Iijima S (1991) Nature 354:56

2. Li H, Eddaoudi M, O'Keeffe M, Yaghi MO (1999) Nature 402:276

3. Beck JS, Vartili JC, Roth WJ, Leonowicz ME, Kresge CT, Schmitt KD, Chu CTW, Olson DH, Sheppard EW, McCullen SB (1992) J Am Chem Soc 114:10834

4. Gregg SJ, Sing KSW (1981) Adsorption, Surface Area and Porosity. Academic: London

5. Zelenak V, Halamova D, Gaberova L, Bloch E, Llewellyn P (2008) Micropor Mesopor Mater 116:358

6. Luo J, Xu H, Liu Y, Zhao Y, Daemen LL, Brown C, Timofeeva TV, Ma S, Zhou HC (2008) J Am Chem Soc 130:9626

7. Park SJ, Jang YS (2003) J Coll Int Sci 261:238

8. Sayari A (1996) Chem Mater 8:1840

9. Chmiola J, Yushin G, Gogotsi Y, Porter C, Simon P, Taberna PL (2006) Science $313: 1760$

10. Kaneko K, Fukuzaki N, Kakei K, Suzuki T, Ozeki S (1989) Langmuir 5:960

11. Iiyama T, Nishikawa K, Suzuki T, Otowa T, Hijiriyama M, Nojima Y, Kaneko K (1997) J Phys Chem B 101:3037

12. Striolo A, Gubbins KE, Gruszkiewicz MS, Cole DR, Simonson JM, Chialvo AA, Cummings PT, Burchell TD, More KL (2005) Langmuir 21:9457

13. Inagaki S, Guan S, Fukushima Y, Ohsuna T, Terasaki O (1999) J Am Chem Soc 121:9611

14. Melde BJ, Holland BT, Blanford CF, Stein A (1999) Chem Mater 11:3302

15. Asefa T, MacLachlan MJ, Coombs N, Ozin GA, (1999) Nature 402:867

16. Inagaki S, Guan S, Ohsuna T, Terasaki O (2002) Nature 416:304 
17. Wang W, Lofgreen JE, Ozin GA (2010) Small 6:2634

18. Comotti A, Bracco S, Valsesia P, Ferretti L, Sozzani P (2007) J Am Chem Soc $129: 8566$

19. Martinez U, Pacchioni G (2010) Micropor Mesopor Mater 129:62

20. Shirai S, Goto Y, Mizoshita N, Ohashi M, Tani T, Shimada T, Hyodo S, Inagaki S (2010) J Phys Chem A 114:6047

21. Jorge M, Gomes JRB, Cordeiro MNDS, Seaton NA (2007) J Am Chem Soc 129:15414

22. Jorge M (2008) Langmuir 24:5714

23. Jorge M, Gomes JRB, Cordeiro MNDS, Seaton NA (2009) J Phys Chem. B 113:708

24. Gomes JRB, Cordeiro MNDS, Jorge M (2008) Geochim Cosmochim Acta 72:4421

25. Becke AD (1993) J Chem Phys 98:5648

26. Lee C, Yang W, Parr RG (1988) Phys Rev B 37:785

27. Frisch MJ, Trucks GW, Schlegel HB, Scuseria GE, Robb MA, Cheeseman JR, Montgomery Jr JA, Vreven T, Kudin KN, Burant JC, Millam JM, Iyengar SS, Tomasi J, Barone V, Mennucci B, Cossi M, Scalmani G, Rega N, Petersson GA, Nakatsuji H, Hada M, Ehara M, Toyota K, Fukuda R, Hasegawa J, Ishida M, Nakajima T, Honda Y, Kitao O, Nakai H, Klene M, Li X, Knox JE, Hratchian HP, Cross JB, Bakken V, Adamo C, Jaramillo J, Gomperts R, Stratmann RE, Yazyev O, Austin AJ, Cammi R, Pomelli C, Ochterski JW, Ayala PY, Morokuma K, Voth GA, Salvador P, Dannenberg JJ, Zakrzewski VG, Dapprich S, Daniels AD, Strain MC, Farkas O, Malick DK, Rabuck AD, Raghavachari K, Foresman JB, Ortiz JV, Cui Q, Baboul AG, Clifford S, Cioslowski J, Stefanov BB, Liu G, Liashenko A, Piskorz P, Komaromi I, Martin RL, Fox DJ, Keith T, Al-Laham MA, Peng CY, Nanayakkara A, Challacombe M, Gill PMW, Johnson B, Chen W, Wong MW, Gonzalez C, Pople JA (2004) Gaussian 03, Revision C.01, Gaussian, Inc., Wallingford CT

28. Šefčík J, McCormick AV (1997) AIChE J 43:2773

29. Mulliken RS (1955) J Chem Phys 23:1833 
30. Breneman CM, Wiberg KB (1990) J Comput Chem 11:361

31. Reed AE, Weinstock RB, Weinhold FA (1985) J Chem Phys 83:735

32. Cerveau G, Corriu RJP, Dabiens B, Bideau JL (2000) Angew Chem Int Ed. 39:4533

33. Jensen F (2007) Introduction to Computational Chemistry. John Wiley \& Sons, Ltd.: Chichester, West Sussex, England

34. Guerra CF, Handgraaf J-W, Baerends EJ, Bickelhaupt FM (2003) J Comput Chem 25:189.

35. Sigfridsson E, Ryde U (1998) J Comput Chem 19:377

36. Carlson HA, Nguyen TB, Orozco M, Jorgensen WL (1993) J Comput Chem 14:1240

37. Murashov V (2003) J. Mol. Struct. 650:141

38. Zwijnenburg MA, Bromley ST, van Alsenoy C, Maschmeyer T (2002) J Phys Chem A 106:12376 